\title{
Evaluation of Structural Costs in Building - Simulation of the Impact of the Height and Column Arrangement
}

\author{
Javier Ferreiro-Cabello ${ }^{1} \quad$ Esteban Fraile-García $^{1} \quad$ Eduardo Martínez de Pisón-Ascacíbar $^{1}$ \\ Emilio Jiménez-Macías ${ }^{2}$ \\ ${ }^{1}$ Department of Mechanical Engineering, University of La Rioja, Spain, \{javier.ferreiro, esteban.fraile, \\ eduardo.mtnezdepison\}@unirioja.es \\ ${ }^{2}$ Department of Electrical Engineering, University of La Rioja, Spain, emilio.jimenez@ unirioja.es
}

\begin{abstract}
Modeling is a useful tool for decision making in the project phases. In the case of reinforced concrete structures, we must be able to locate representative parameters in order to optimize costs. This paper assesses the impact of the column arrangement and building height. The variation of the costs for the foundation and two floor interaxis are discussed. The results are assessed by the ratio of cost per square meter executed. The optimization of the geometry of the building is determined by the interaxis distances and the selected structural thickness. In the case studied the arrangement of the pillars in a $6 \times 6$ meters grid using 4 heights offers the best economic results.
\end{abstract}

Keywords: reinforced concrete, costs, columns arrangement, structures, modeling

\section{Introduction}

The decisions made in the early stages of a project have a significant impact on its future development. The economic costs can and should be dimensioned so that the investor has the smallest possible uncertainties. Despite this construction projects have a long deployment time that introduces those unwanted uncertainties. This work focuses on structural solutions through the use of reinforced concrete (Amir, 2013; CTE, 2006; CYPECAD, 2015).

The intensive application of reinforced concrete has been produced largely by the advancement and study of the behavior of new materials and the development of new technologies. This is the origin of structural engineering that deals with the conception, design and construction of structures emerged. We want to emphasize that in the same way that society evolves, technology, materials and available tools do (De Albuquerque et al, 2012; Delijani et al, 2015; EHE-08 2008).

The structural solution costs represent a significant percentage within any project. With an eye to the future by implementing algorithms it is necessary to know the impact of different variables that affect the final cost of a given solution (Fernández-Ceniceros et al, 2010; Kaveh et al, 2011; Koksal et al, 2013).

As representative geometric variables in the definition of one building they have been considered the number of pillars or columns and the height of the building. For the structural solution of the floors a bidirectional forged or slab structure recoverable coffer with a constant structural depth has implemented, but modifying the interaxis (Moretti, 2014; Poluraju et al, 2012; Porwal and Hewage, 2012).

This range of solutions is made by using three elements mainly: Concrete, steel and formwork elements.

\section{Proposed Methodology}

The proposed methodology focuses on assessing the economic impact incurred in the process of building a reinforced concrete structure assuming that the reticular forged recoverable coffer is selected for the horizontal structure. This choice is not accidental because, it presents some remarkable features:

- Materials incorporated to the structure are permanently only two, in this case steel and concrete. In all cases it is used concrete HA-25/P/20/IIa and steel B-500S.

- In this case the difference in the performance of each alternative is faithfully reflected in the variation of the quantities consumed of steel and concrete.

- The use of recoverable coffer.

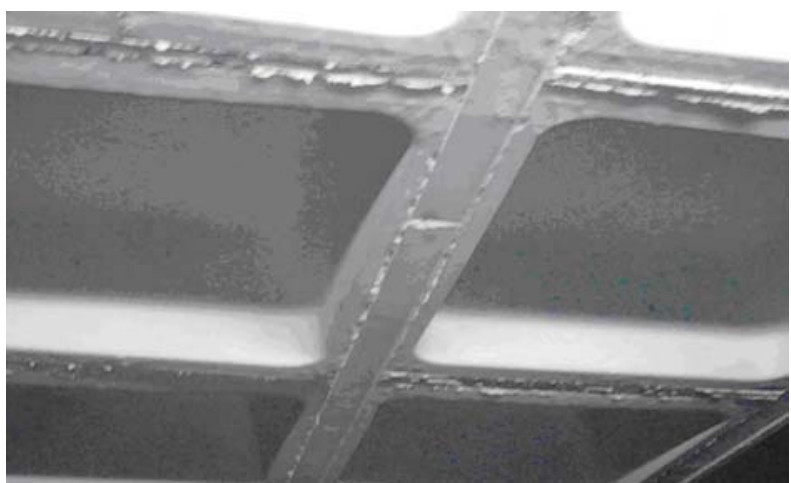

Figure 1. Final result after removal of the provisional formwork. 
To execute these structures, once consolidated the pillars, a framework is used (Figure 1). Once the structure consolidates these elements are retrieved and used in subsequent structures. For the assessment of costs it is important to establish the number of uses. In this paper this variable is 50 .

Obviously the cost of a structure will be lower when the material consumption are optimized (reducing the amounts of concrete and steel) and the use of formwork materials and labor.

The proposal is to make the modeling of a square building of dimensions $24 \times 24$ meters using different arrangements of columns and number of plants (Figure 2 ). For the arrangement of pillars three values of the grid have been selected: a situation of short lights of $4 \times 4$ meters, another common situation in building alternative of $6 \times 6$ meters, and $8 \times 8$ meters with overhead lights. The modeled cases include 4 floors, 6 floors, 8 floors and 10 floors. The buildings have a height on the ground floor of 4 meters and the rest of floor slabs with heights of 3 meters, devoting the last forged to a flat roof.

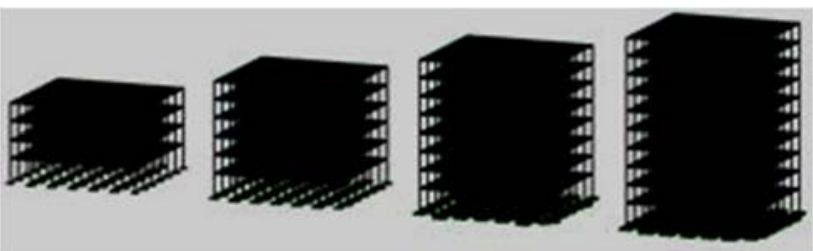

Figure 2. Modelling buildings.

All the floors have been solved using a structural depth of 30 centimeters ( 25 of box more $5 \mathrm{~cm}$ of compression layer). The distances of the models are varied using two discrete solutions of 60 and 80 centimeters (Figure 3), the width of nerve and the coating remained constant. Thus the own weights of the two alternatives of the implemented floor slab are $4.70 \mathrm{kN} / \mathrm{m}^{2}$ and $4.03 \mathrm{kN} / \mathrm{m}^{2}$ respectively.

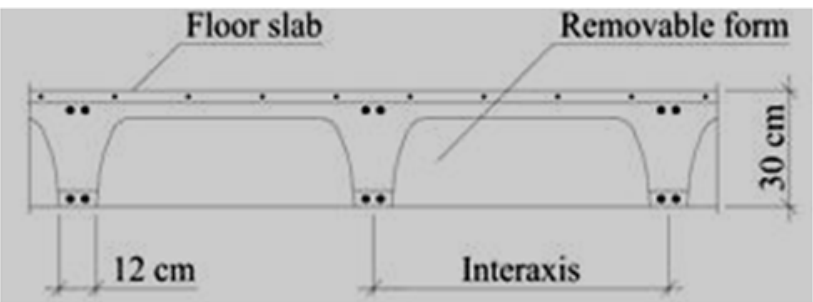

Figure 3. Alternative sections of implemented floors.

Regarding the considered loads, facade loads have been introduced as uniform loads on the perimeters of the floors with a value of $7 \mathrm{kN} / \mathrm{m}$, and on deck this value is reduced to $3 \mathrm{kN} / \mathrm{m}$. For surface loads on the floors $2 \mathrm{kN} / \mathrm{m}^{2}$ has been considered for permanent loads and $2 \mathrm{kN} / \mathrm{m}^{2}$ for overhead use. In the cover these values have changed, $3 \mathrm{kN} / \mathrm{m}^{2}$ for permanent loads and $1 \mathrm{kN} / \mathrm{m}^{2}$ for overload use. Wind loads were implemented considering the Spanish legislation and snow loads are included in overload considered indoor use. For dimensioning the foundation, it has been considered an average benefit in the soil bearing capacity, on the maximum permissible stress, $0.2 \mathrm{~N} / \mathrm{mm}^{2}$.

Table 1. Unit Cost Items Considered.

\begin{tabular}{|l|c|}
\hline Description & $\begin{array}{c}\text { Cost } \\
\text { (€) }\end{array}$ \\
\hline $\mathrm{m}^{2}$ System formwork foundation plinth. & 19.94 \\
\hline $\mathrm{m}^{2}$ lean concrete layer (thickness 0.1 m). & 10.22 \\
\hline $\begin{array}{l}\mathrm{m}^{3} \text { foundation of reinforced concrete, concrete made with } \\
\text { HA-25/P/20/IIa manufactured in plant, and discharge from } \\
\text { truck. }\end{array}$ & 104. \\
\hline $\begin{array}{l}\text { Reinforcing steel kg UNE-EN 10080 B 500 S, developed } \\
\text { in industrial workshop. Including transportation and } \\
\text { placement work. }\end{array}$ & 1.00 \\
\hline $\begin{array}{l}\mathrm{m}^{3} \text { of concrete for pillars made of concrete HA-25/P/20/IIa } \\
\text { manufactured in central and poured with cupolas, } \\
\text { assembly and disassembly of reusable formwork system } \\
\text { metal sheets. }\end{array}$ & 349.65 \\
\hline $\begin{array}{l}\text { Reticular }{ }^{2} \text {, total depth 30=25+5 cm, made with concrete } \\
\text { HA-25/P/20/IIa manufactured in central; discharge with } \\
\text { pump on continuous formwork system; nerves "in situ" 12 } \\
\text { cm, welded wire in compression layer. No impact of } \\
\text { pillars. }\end{array}$ & 37.60 \\
\hline $\begin{array}{l}\text { Unites of recoverable formwork PVC, 76x80x25 cm for } \\
50 \text { uses, including special pieces. }\end{array}$ & 2.29 \\
\hline $\begin{array}{l}\text { Unites of recoverable formwork PVC, 56x60x25 cm for } \\
50 \text { uses, including special pieces. }\end{array}$ & 1.75 \\
\hline $\begin{array}{l}\mathrm{m}^{3} \text { of concrete for slabs manufactured in Central HA- } \\
25 / \mathrm{P} / 20 / I I a .\end{array}$ & 76.88 \\
\hline
\end{tabular}

The definition of the structure will be made following the Spanish legislation and using a structural calculation software tool named CYPECAD. Performing calculations provides data on the consumption of materials, which in the selected type represent significant values used in the comparison. By using a database of construction, the prices of each of the studied alternatives are obtained.

Table 2. Items Considered for Each Block Of The Structure.

\begin{tabular}{|c|c|c|}
\hline \multirow{4}{*}{ foundation } & items & units \\
\cline { 2 - 3 } & Cleaning concrete HL-15 / P / 20 & $\mathrm{m}^{3}$ \\
\cline { 2 - 3 } & Reinforcing steel B 500 S & $\mathrm{kg}$ \\
\cline { 2 - 3 } & Concrete HA-25 / P / 20/ IIa & $\mathrm{m}^{3}$ \\
\hline \multirow{3}{*}{ columns } & Shuttering fundation & $\mathrm{m}^{2}$ \\
\cline { 2 - 3 } & Column formwork & $\mathrm{m}^{2}$ \\
\cline { 2 - 3 } & Reinforcing steel B 500 S & $\mathrm{kg}$ \\
\hline \multirow{3}{*}{ floor } & Concrete HA-25 / P / 20/ IIa & $\mathrm{m}^{3}$ \\
\cline { 2 - 3 } & Formwork wrought & $\mathrm{m}^{2}$ \\
\cline { 2 - 3 } & Reinforcing steel B 500 S & $\mathrm{m}^{3}$ \\
\cline { 2 - 3 } & Concrete HA-25 / P / 20 / IIa & $\mathrm{units}^{3}$ \\
\hline
\end{tabular}


The cost of the structure is divided into three sections: foundation, pillars or columns and floor. This scheme follows the construction process, and the prices for the various items are presented in Table 1.
These prices combined with the results of consumption of each alternative allow us to obtain the costs of the proposed solutions. Table 2 lists the items that are incorporated in each block with the units used.

Table 3. Consumption Obtained for Each Solution

\begin{tabular}{|c|c|c|c|c|c|c|c|c|c|c|c|c|}
\hline & & & & onsump & on Fou & tion & & imption $p$ & & & ed consum & \\
\hline I (cm) & $R$ (mxm) & $\mathbf{H}\left(\mathbf{n}^{0}\right)$ & $\begin{array}{c}\mathbf{H L} \\
\left(\mathbf{m}^{3}\right)\end{array}$ & $\begin{array}{c}\mathrm{Fe} \\
(\mathrm{kg})\end{array}$ & $\begin{array}{c}\text { HA } \\
\left(\mathbf{m}^{\mathbf{3}}\right)\end{array}$ & $\mathbf{E}\left(\mathbf{m}^{2}\right)$ & $\mathbf{E}\left(\mathbf{m}^{2}\right)$ & $\mathrm{Fe}(\mathrm{kg})$ & HA $\left(\mathrm{m}^{3}\right)$ & $\mathrm{Fe}(\mathrm{kg})$ & HA $\left(\mathbf{m}^{3}\right)$ & $\mathrm{C}(\mathbf{U d})$ \\
\hline \multirow{12}{*}{60} & \multirow{4}{*}{$4 \times 4$} & 4 & 15 & 2196 & 55 & 125 & 694 & 4238 & 51 & 16213 & 537 & 4224 \\
\hline & & 6 & 23 & 3761 & 116 & 210 & 1011 & 7040 & 75 & 24841 & 805 & 6336 \\
\hline & & 8 & 32 & 6347 & 238 & 368 & 1341 & 11573 & 100 & 34570 & 1073 & 8448 \\
\hline & & 10 & 41 & 1068 & 366 & 499 & 1674 & 22563 & 126 & 46543 & 1341 & 10560 \\
\hline & \multirow{4}{*}{$6 \times 6$} & 4 & 14 & 2660 & 96 & 151 & 360 & 3507 & 27 & 23555 & 497 & 5184 \\
\hline & & 6 & 22 & 5307 & 201 & 260 & 539 & 8792 & 42 & 37219 & 746 & 7776 \\
\hline & & 8 & 30 & 9095 & 307 & 344 & 736 & 16570 & 60 & 53793 & 994 & 10368 \\
\hline & & 10 & 38 & 11921 & 397 & 396 & 965 & 24209 & 85 & 75531 & 1242 & 12960 \\
\hline & \multirow{4}{*}{$8 \times 8$} & 4 & 14 & 3659 & 143 & 182 & 250 & 5538 & 21 & 40697 & 492 & 5272 \\
\hline & & 6 & 22 & 6752 & 232 & 236 & 383 & 13554 & 34 & 63716 & 738 & 7908 \\
\hline & & 8 & 31 & 11011 & 356 & 307 & 541 & 20154 & 52 & 91923 & 984 & 10544 \\
\hline & & 10 & 38 & 14444 & 463 & 356 & 720 & 27793 & 76 & 125531 & 1230 & 13180 \\
\hline \multirow{12}{*}{80} & \multirow{4}{*}{$4 X 4$} & 4 & 16 & 2279 & 62 & 137 & 694 & 4238 & 51 & 16544 & 576 & 1512 \\
\hline & & 6 & 24 & 4149 & 127 & 226 & 1011 & 7350 & 75 & 25603 & 864 & 2268 \\
\hline & & 8 & 33 & 6389 & 264 & 402 & 1347 & 12259 & 101 & 36131 & 1151 & 3024 \\
\hline & & 10 & 42 & 11294 & 372 & 503 & 1678 & 23405 & 127 & 49036 & 1439 & 3780 \\
\hline & \multirow{4}{*}{$6 \times 6$} & 4 & 14 & 2385 & 89 & 145 & 360 & 3284 & 27 & 21524 & 451 & 2820 \\
\hline & & 6 & 21 & 5007 & 186 & 249 & 539 & 8409 & 42 & 34075 & 677 & 4230 \\
\hline & & 8 & 29 & 8314 & 293 & 335 & 733 & 15580 & 60 & 50216 & 902 & 5640 \\
\hline & & 10 & 37 & 11400 & 376 & 385 & 957 & 26114 & 83 & 70901 & 1128 & 7050 \\
\hline & \multirow{4}{*}{$8 \times 8$} & 4 & 14 & 3329 & 137 & 176 & 250 & 5322 & 21 & 39751 & 446 & 2880 \\
\hline & & 6 & 21 & 6618 & 217 & 228 & 385 & 12518 & 34 & 63391 & 669 & 4320 \\
\hline & & 8 & 29 & 10405 & 333 & 297 & 534 & 19485 & 51 & 91053 & 892 & 5760 \\
\hline & & 10 & 37 & 13885 & 446 & 347 & 713 & 26657 & 74 & 124024 & 1115 & 7200 \\
\hline
\end{tabular}

Table 4. Costs of Different Structural Proposals

\begin{tabular}{|c|c|c|c|c|c|c|c|}
\hline I (cm) & R (mxm) & $H\left(n^{0}\right)$ & $€$ Foundation & $€$ Pillars & $€$ Slabs & $€$ Structure & $€ / \mathrm{m}^{2}$ \\
\hline \multirow{12}{*}{60} & \multirow{4}{*}{$4 \times 4$} & 4 & 12.006 & 22.227 & 153.676 & 187.910 & 79,6 \\
\hline & & 6 & 22.359 & 33.253 & 231.036 & 286.648 & 80,9 \\
\hline & & 8 & 41.832 & 46.681 & 309.484 & 397.997 & 84,2 \\
\hline & & 10 & 53.482 & 66.776 & 390.169 & 510.427 & 86,4 \\
\hline & \multirow{4}{*}{$6 \times 6$} & 4 & 17.238 & 13.021 & 159.665 & 189.924 & 80,4 \\
\hline & & 6 & 33.829 & 23.554 & 241.381 & 298.765 & 84,3 \\
\hline & & 8 & 51.199 & 37.703 & 325.983 & 414.885 & 87,8 \\
\hline & & 10 & 65.340 & 53.866 & 415.772 & 534.979 & 90,6 \\
\hline & \multirow{4}{*}{$8 \times 8$} & 4 & 23.751 & 12.783 & 176.604 & 213.138 & 90,2 \\
\hline & & 6 & 38.042 & 25.428 & 267.555 & 331.025 & 93,4 \\
\hline & & 8 & 57.571 & 38.350 & 363.709 & 459.630 & 97,3 \\
\hline & & 10 & 73.916 & 54.227 & 465.260 & 593.403 & 100,5 \\
\hline \multirow{12}{*}{80} & \multirow{4}{*}{$4 \times 4$} & 4 & 13.142 & 22.227 & 153.081 & 188.450 & 79,8 \\
\hline & & 6 & 24.388 & 33.563 & 230.408 & 288.360 & 81,4 \\
\hline & & 8 & 45.407 & 47.703 & 309.187 & 402.296 & 85,2 \\
\hline & & 10 & 64.508 & 67.870 & 390.341 & 522.720 & 88,5 \\
\hline & \multirow{4}{*}{$6 \times 6$} & 4 & 16.051 & 12.798 & 151.484 & 180.333 & 76,3 \\
\hline & & 6 & 31.572 & 23.140 & 229.006 & 283.717 & 80,1 \\
\hline & & 8 & 48.681 & 36.521 & 310.108 & 395.310 & 83,7 \\
\hline & & 10 & 62.185 & 55.289 & 395.787 & 513.261 & 86,9 \\
\hline & \multirow{4}{*}{$8 \times 8$} & 4 & 22.591 & 12.567 & 169.490 & 204.647 & 86,6 \\
\hline & & 6 & 36.097 & 24.518 & 257.979 & 318.594 & 89,9 \\
\hline & & 8 & 54.148 & 37.247 & 350.499 & 441.894 & 93,5 \\
\hline & & 10 & 71.244 & 52.629 & 448.337 & 572.209 & 96,9 \\
\hline
\end{tabular}




\section{Objective}

The main objective is to have a vision of the cost of the entire structure. The inclusion of three variables will allow to compare different alternatives and select the one that is most viable from the economic point of view.

The novelty lies on the inclusion of variations in the geometry of the building (arrangement of the pillars and building height) combined with the definition of the structural solution used (forged 60x60 and 80x80 centimeters interaxis).

To facilitate the monitoring of the cost of the structure it has been divided into three blocks with a different treatment. The foundation with four blocks for the lean concrete, steel foundation, structural concrete and formwork needed. The pillars are elements with a production process in which the cleaning concrete disappears, repeating the previous three blocks and presenting totally different yields.

\section{Case study}

Performing calculations by regulations currently in use in Spain determines the technically viable alternatives. From those viable solutions, material consumption are found: steel, concrete and auxiliary elements (formwork and caissons) at different values for each block of the structure; the data are reflected in Table 3. The modeling analysis allows controlling deformations and adapting the optimal arrangement of the structure, all rigorously complying with current regulations.

Known data set consumption and prices of each item can determine the cost of each alternative as reflected in Table 4.

The production cost is done add the amount of each item. In this case we have taken into account the variations in consumption of both materials and auxiliary means necessary.

The total cost of the structure has been obtained and the graphical representation of the results is divided into two blocks. Figure 4 represents the impact of each block in each studied alternative.

For this configuration of the floor inside buildings of four floors, solution employing fewer supports $(8 \times 8)$ has a total cost that is $13.43 \%$ higher than the alternative with the highest number of supports $(4 \times 4)$. In the case of solutions for buildings of 10 floors this difference becomes greater resulting in a $16.26 \%$. If we analize the results in regard to the foundations these values are completely different in low buildings since the cost of the foundation is increased by $97.83 \%$ whereas in tall buildings the decreased number of pillars an increase of $38.21 \%$. Reducing the number of supports makes the starting pillars decrease.

With 60x60 interaxis configuration total costs increase as the number of carriers it is reduced for all modeled buildings.

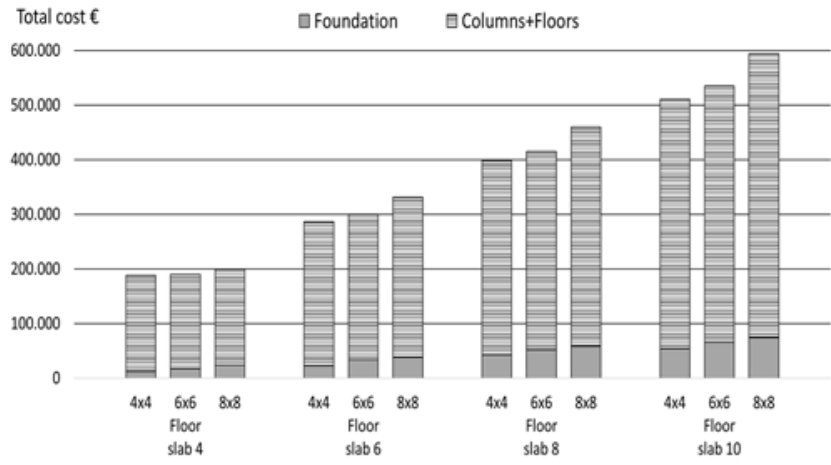

Figure 4. Total cost alternatives interaxis $60 \times 60$.

The results for structural solutions that employ larger interaxis $(80 \times 80)$ are shown in Figure 5.

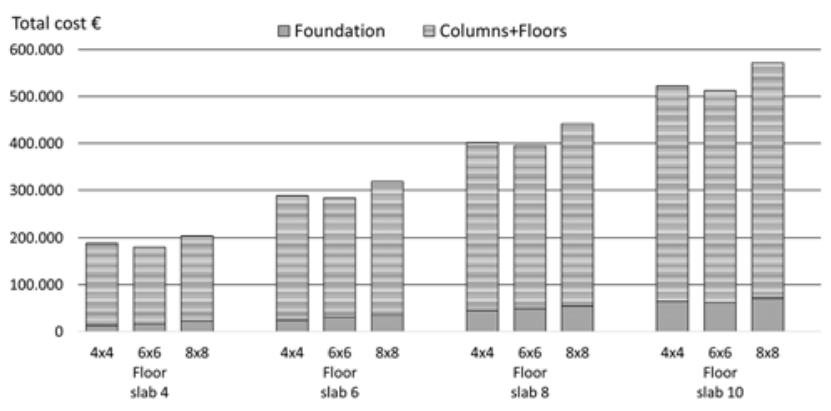

Figure 5. Total cost alternative interaxis $80 \times 80$.

For this configuration of the floor inside buildings of four floor employing fewer supports $(8 \times 8)$ has a total cost which is $8.59 \%$ higher than the alternative with the highest number of supports $(4 \times 4)$. In the case of buildings of 10 floors this difference becomes greater resulting in a $9.47 \%$. If we analyze the results in regard to the foundations these values are completely different in low buildings since the cost of the foundation is increased by $71.90 \%$ whereas in tall buildings the decreased number of pillars drives to an increase of $10.44 \%$. Reducing the number of supports makes the starting pillars decrease and the cost of the slabs being greater increases in recent increases.

This configuration of the floor, increasing the interaxis, allows better solutions in total cost when the $6 \times 6$ grid for the same height of the building is implemented. In the four heights minimum cost values are obtained.

Solutions with more supports $(4 \times 4)$ have similar costs for both interaxis being lower in 60 . The differences are below $2.40 \%$. Solutions with fewer brackets $(8 \times 8)$ costs are similar, being lower in 80 . The resulting differences are extended below $4.01 \%$.

While these results are interesting, we consider much more relevant to compare the ratios of the structural solution. In this case the cost per executed square meter is analyzed, and the numerical results are reflected in the 
last column of Table 4, while graphical results are presented jointly for both interaxis in Figure 6.

The extreme values have a variation of $31.72 \%$ and are:

- The minimum cost $76.3 € / \mathrm{m} 2$ for a building of 4 heights with me interaxis $6 \times 6$ grid $80 \mathrm{~cm}$.

- The maximum cost $100.5 € / \mathrm{m} 2$ for a building of 10 heights with me interaxis $8 \times 8$ grid $60 \mathrm{~cm}$.

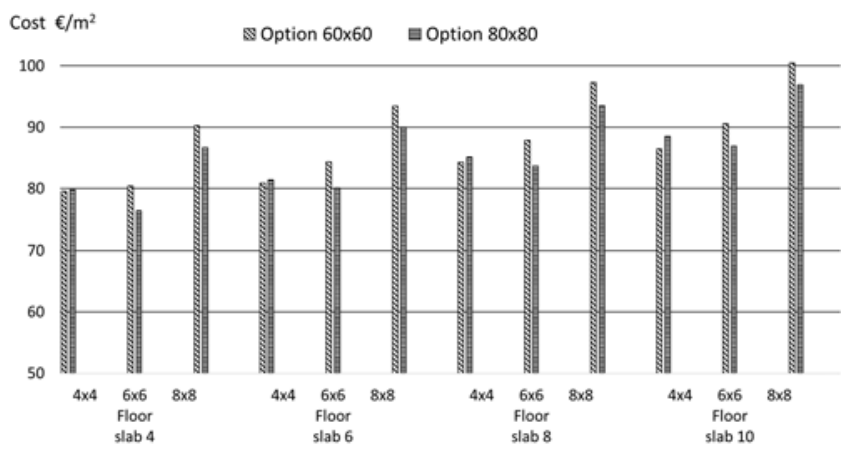

Figure 6. Ratio of cost $€ / \mathrm{m} 2$ different alternatives

Interaxis solutions by $60 \mathrm{~cm}$ range from $79.6 € / \mathrm{m} 2$ for buildings of 4 heights and $4 \times 4$ grid to $100.5 € / \mathrm{m} 2$ in the case of 10 heights and $8 \times 8$ grid. This is a variation of $26.26 \%$. For proposals by interaxis $80 \mathrm{~cm}$ range from $76.3 € / \mathrm{m} 2$ for buildings of 4 heights and $6 \times 6$ grid to $96.9 € / \mathrm{m} 2$ in the case of 10 heights and $8 \times 8$ grid. This is a variation of $27.00 \%$

\section{Conclusions}

As a preliminary conclusion, it is noteworthy that variations make that the results present significant oscillations. The own reinforced concrete structural definition incorporates decisions affecting the cost produced in the design phase and implementation.

The tool implemented here is very useful when combined and incorporated the cost or impact of the land on which it is intended to build. The combination of both values allows the designer to locate a lower cost alternative.

Disregarding the impact of the land, and for a structural thickness of 30 centimeters, the most economical solutions are located in low buildings of $6 \times 6$ meters grid and interaxis distances of 80 centimeters. The worst alternative is located when employed 60 centimeters interaxis and reticles of $8 \times 8$ meters.

Structurally, the 30 centimeter thickness is oversized for reticles of $4 \times 4$ meters and it presents very high amounts of steel for reinforcement grids of $8 \times 8$ meters. This is the reason why the best solutions appear in the grid of $6 \times 6$ meters. This phenomenon is more pronounced when increasing the interaxis distances. This is one of the reasons why this is the most used structural thickness in structures in buildings in Spain.

This novelty presents a clear practical application to real cases, since the casestudy has been selected only as a way to present the proposed methodology based on the ratio of cost per square meter executed, but the methodology is widely applied to real cases. In fact, this piece of research is based on the information obtained from thousands of real cases, from a building interprise, which have also been used to validate the proposal.

Furthermore, the use of the results of this work by the designer permits the optimization of the decisions based on the conclusions obtained in the general case.

\section{References}

O. Amir. A topology optimization procedure for reinforced concrete structures. Computers \& Structures, 114:46-58, 2013.

CTE. "Código Técnico de la Edificación", translated as Technical Building Code. Royal Decree 314/2006, of March 17, of the Ministry of Housing (Spain), 2006.

CYPECAD "CYPE Ingenieros, Software para Arquitectura, Ingeniería y Construcción", translated as CYPE Engineers, Software for Architecture, Engineering and Construction. CYPE Ingenieros S.A., 2015.

A.T. De Albuquerque, M.K. El Debs, and A.M.C. Melo. A cost optimization-based design of precast concrete floors using genetic algorithms. Automation in Construction, 22:348-356, 2012.

F.Delijani, M.West, and D. Svecova,. The evaluation of change in concrete strength due to fabric formwork. Journal of Green Building, 10(2):113-133, 2015.

EHE-08 "Instrucción de Hormigón Estructural" translated as Structural Concrete Instruction, Royal Decree 1247/2008, of July 18, of the Ministry of Public Works (Spain).

J. Fernández-Ceniceros, E. Martínez-De-Pisón, F.J. MartínezDe-Pisón, R. Lostado-Lorza, and L. Celorrio. "Optimización de costes en estructuras de hormigón mediante técnicas de minería de datos. Aplicación a forjados unidireccionales" translated as Cost optimization in concrete structures using data mining techniques. Application to unidirectional slabs, XIV International Congress on Project Engineering, Madrid (Spain), 2010.

A. Kaveh, and A. Shakouri Mahmud Abadi. Cost Optimization of Reinforced Concrete One-Way Ribbed Slabs Using Harmony Search Algorithm, Arabian Journal for Science and Engineering, 36(7):1179-1187, 2011.

F. Koksal, A. Ilki., and M.A. Tasdemir. Optimum Mix Design of Steel-Fibre-Reinforced Concrete Plates, Arabian Journal for Science and Engineering, 38(11):2971-2983, 2013.

L. Moretti. Technical and economic sustainability of concrete pavements. Modern Applied Science, 8(3):1-9, 2014.

P. Poluraju, K. Dorji, P. Rai, T. Wangchuk, and Tharchen. Economic design of concrete structure through judicious selection of materials at the early stage of design phase. International Journal of Earth Sciences and Engineering, 5(2):358-362, 2012.

A. Porwal, and K.N. Hewage. Building information modelingbased analysis to minimize waste rate of structural reinforcement. Journal of Construction Engineering and Management, 138(8):943-954, 2012. 